\title{
Composição em ácidos graxos dos tecidos de frangos de corte alimentados com subprodutos de maracujá ${ }^{1}$
}

\author{
Cristina Kimie Togashi², José Brandão Fonseca ${ }^{3}$, Rita da Trindade Ribeiro Nobre Soares ${ }^{3}$, \\ Arlene Gaspar ${ }^{4}$, Edenio Detmann ${ }^{5}$
}

\author{
${ }^{1}$ Projeto financiado pela FAPERJ. \\ 2 Pólo Regional da Alta Paulista - Adamantina, SP - DDD/APTA/SAA-SP. \\ 3 UENF/CCTA/LZNA. Av. Alberto Lamego, 2000, Campos dos Goytacazes, RJ, CEP: 28015150. \\ ${ }^{4}$ Departamento de Tecnologia de Alimentos - IT/UFRRJ, $\mathrm{Br} 465, \mathrm{Km} 7$, Seropédica, RJ. \\ ${ }^{5}$ DZO/CCA/UFV.
}

RESUMO - A composição em ácidos graxos de tecidos de frangos de corte foi avaliada utilizando-se 200 pintos machos Cobb criados a partir dos 22 dias de idade com rações experimentais compostas de milho e farelo de soja suplementadas com 4 ou 8\% de casca de maracujá e 4 ou 8\% de semente de maracujá. O delineamento experimental utilizado foi o inteiramente casualizado em modelo fatorial $2 \times 2$ com um tratamento adicional (controle, $0 \%$ de subproduto de maracujá), com quatro repetições e dez aves por unidade experimental. Foram utilizados contrastes ortogonais com dois níveis de suplementação e dois tipos de subproduto. As aves foram abatidas aos 42 dias de idade para análises da composição em ácidos graxos. A utilização de semente de maracujá reduziu o conteúdo de ácidos palmítico C16:0, esteárico C18:0 e docosahexaenóico C22:6 do peito. Na perna, os subprodutos de maracujá aumentaram o teor de ácido linoléico C18:2, linolênico C18:3 e palmítico C16:0 e reduziram o de C18:0, ácido esteárico.

Palavras-chave: avicultura, características de carcaça, composição química

\section{Composition of fatty acids in tissues of broilers fed by-products of passion fruit}

\begin{abstract}
The fatty acids composition of broiler tissue was evaluated using two hundred male Cobb chicks. They were raised from 22 days of age with experimental diets based on corn and soybean meal supplemented with 4 or $8 \%$ of passion fruit peel and 4 or $8 \%$ of passion fruit seed. A completely randomized experimental design was used with a 2 x 2 factorial arrangement with an additional treatment (Control, $0 \%$ of passion fruit byproducts), with four replications and ten birds per experimental unit. A orthogonal contrast with two levels of supplementation and two types of byproducts., The birds were slaughtered at 42 days of age for fatty acids composition analyses. The use of passion fruit seed reduced the content of palmitic C16:0, estearic C18:0 and docosahexaenoic acid C22:6 in the breast. In the leg, passion fruit byproducts increased the content of linoleic C18:2, linolenic C18:3 and palmitic acid C16:0 and reduced the content of estearic acid C18:0.
\end{abstract}

Key Words: poultry, carcass characteristic, chemical composition

\section{Introdução}

O Brasil é o maior produtor e exportador de suco concentrado de maracujá. Os principais subprodutos da extração do suco de maracujá são as cascas e as sementes resultantes de seu processamento, que correspondem de 65 a 70\% do peso do fruto (Oliveira et al., 2002) e que, na maioria das vezes, não são aproveitados, tornando-se um grande problema ambiental.

As sementes do maracujá são consideradas boa fonte de ácido graxo essencial, que pode ser utilizado nas indústrias alimentícia e cosmética. O ácido linoléico (ômega 6) é um dos principais ácidos graxos encontrados na composição do óleo da semente de maracujá (55 a 66\%), seguido pelo ácido oléico (18 a 20\%) e pelo ácido palmítico (10 a 14\%). O ácido linolênico (ômega 3) é o de mais baixa proporção e corresponde a 0,8 a $1 \%$ do total dos ácidos graxos (Leonel et al., 2000).

Os ácidos graxos são os principais elementos dos triacilgliceróis, componentes de óleos e gorduras comestíveis e que representam 95\% dos lipídeos da dieta humana. Constituem as principais formas de armazenamento de energia nos animais (adipócitos) e vegetais (sementes). Alguns ácidos poliinsaturados (PUFA), como o linoléico (n-6) e 
linolênico (n-3), são considerados essenciais na dieta, uma vez que homens e animais são incapazes de sintetizá-los.

Pesquisas têm estabelecido que a composição das carcaças de aves pode ser alterada pelo tipo e pela quantidade de ácidos graxos da dieta. O consumo de dietas suplementadas com ácidos graxos insaturados possibilita a deposição desses ácidos nos tecidos (Marion \& Woodroof 1963; Ajuyah et al., 1991; Hrdinka et al., 1996). No entanto, o grau de saturação das gorduras nas dietas afeta seu uso metabólico e o acúmulo de gordura nos frangos (Pinchasov \& Nir, 1992; Sanz et al., 2000). Os ácidos graxos poliinsaturados produzem menor deposição de gordura em comparação aos saturados e aos monoinsaturados (Crespo \& Garcia, 2001).

Este trabalho foi realizado com o objetivo de estudar os efeitos da inclusão de resíduos do processamento do maracujá na alimentação sobre as características de carcaça e a composição de ácidos graxos dos tecidos de frangos de corte.

\section{Material e Métodos}

O experimento foi conduzido no Setor de Avicultura da Unidade de Apoio à Pesquisa em Zootecnia do LZNA/ CCTA/UENF, em Campos dos Goytacazes, RJ.

Foram utilizados 200 pintos de corte Cobb criados de acordo com instruções do manual de criação da linhagem. As aves foram distribuídas ao acaso em um galpão de alvenaria coberto com telhas de barro, com cortinas e telas nas laterais, contendo 20 boxes experimentais $(1,5 \times 2,0 \mathrm{~m})$. Cada unidade experimental foi composta de dez aves, distribuídas em boxes equipados com um comedouro tubular e um bebedouro pendular. Água e ração foram fornecidas à vontade.

Avaliaram-se cinco rações compostas de milho e farelo de soja suplementadas com dois níveis de casca e dois níveis de semente de maracujá (Tabela 1) e uma ração testemunha, à base de milho e farelo de soja. As aves foram alimentadas com uma ração inicial durante os primeiros 21 dias de idade e depois com uma ração experimental no período de 22 a 42 dias de idade.

As sementes e cascas de maracujá foram processadas e, após extração do suco, foram separadas, secas ao ar livre por um período de 3 a 5 dias, com viragens periódicas para melhorar a aeração e facilitar a secagem. Depois de secos, os subprodutos foram triturados e adicionados às rações (Tabela 2). A variação no tempo de secagem decorreu das condições climáticas.

Os níveis de suplementação de semente e casca de maracujá (4 e 8\%) foram baseados no trabalho realizado por
Tabela 1 - Composição química dos subprodutos de maracujá Table 1 - Chemical composition of passion fruit byproducts

\begin{tabular}{lrr}
$\begin{array}{l}\text { Composição } \\
\text { Composition }\end{array}$ & $\begin{array}{c}\text { Casca } \\
\text { Peel }\end{array}$ & $\begin{array}{c}\text { Semente } \\
\text { Seed }\end{array}$ \\
\hline Umidade (Moisture), \% & $89,08(2)$ & $6,60(1)$ \\
Lipídeos (Lipids), \% & $0,70(2)$ & $24,5(1)$ \\
Proteína bruta (Crude protein), \% ${ }^{3}$ & 12,45 & 14,45 \\
Fibra bruta (Crude fiber), \% ${ }^{4}$ & 3,61 & 30,97 \\
Energia bruta (Gross energy), kcal/ $/ \mathrm{kg}^{4}$ & $3.655,57$ & $3.311,65$ \\
Cinzas (Ash), \% & $0,92{ }^{(2)}$ & $1,4{ }^{(1)}$ \\
\hline${ }^{1}$ Chau \& Huang (2004), ${ }^{2}$ Oliveira et al. (2002), ${ }^{3}$ Laboratório de Zootecnia \\
e Nutrição Animal CCTA/UENF (\% MS) (\% DM), ${ }^{4}$ Universidade Federal \\
Rural do Rio de Janeiro - DNAP/IZ.
\end{tabular}

Ariki et al. (1977), que não verificaram nenhuma influência desses níveis nos parâmetros de desempenho produtivo dos animais.

A ração sem semente e casca de maracujá foi formulada de acordo com as recomendações nutricionais de Rostagno (2000) (Tabela 2). Os valores de energia metabolizável considerados para a casca e semente de maracujá foram de 1.813 e $1.635 \mathrm{kcal} / \mathrm{kg}$, respectivamente, apresentados por Ariki et al. (1977). Todos os ingredientes foram pesados individualmente e homogeneizados em um misturador tipo Y por 15 minutos.

O nível de óleo de soja adicionado às rações foi fixado para não influenciar o teor total de ácido linoléico nas rações, uma vez que o óleo de soja é rico neste ácido graxo. Não foi determinado o teor de ácido linoléico nos subprodutos utilizados neste experimento.

Aos 42 dias de idade, duas aves de cada unidade experimental mantidas em jejum alimentar de 12 horas foram abatidas, evisceradas e os cortes de peito e perna (coxa+sobrecoxa) foram utilizados para determinação do teor de gordura e de ácidos graxos nos tecidos. O fígado, a moela e a gordura abdominal (encontrada na região próxima à cloaca) de cada animal foram retirados, pesados e acondicionados individualmente em embalagens plásticas.

Amostras compostas das duas aves abatidas foram obtidas e misturadas a duas amostras da mesma repetição. No total, foram obtidas 20 amostras de peito e 20 de perna (coxa + sobrecoxa). Os cortes foram desossados, acondicionados em sacos plásticos, embrulhados em papel alumínio para reduzir os efeitos de oxidação e armazenados a $-20^{\circ} \mathrm{C}$. Após o descongelamento, as peles foram retiradas dos cortes, que foram moídos em processador doméstico e homogeneizados para análises no Laboratório de Zootecnia e Nutrição Animal CCTA/UENF e no Departamento de Tecnologia de Alimentos do Instituto de Tecnologia de Alimentos da UFRRJ. 
Tabela 2 - Composição das rações experimentais

Table 2 - Composition of the experimental diets

\begin{tabular}{|c|c|c|c|c|c|}
\hline \multirow[t]{3}{*}{$\begin{array}{l}\text { Ingrediente (kg) } \\
\text { Ingredient }\end{array}$} & \multicolumn{5}{|c|}{$\begin{array}{c}\text { Ração } \\
\text { Diet }\end{array}$} \\
\hline & \multirow{2}{*}{$\begin{array}{c}\text { Controle (\%) } \\
\text { Control } \\
0\end{array}$} & \multicolumn{2}{|c|}{$\begin{array}{c}\text { Casca (\%) } \\
\text { Peel }\end{array}$} & \multicolumn{2}{|c|}{$\begin{array}{c}\text { Semente (\%) } \\
\text { Seed }\end{array}$} \\
\hline & & 4 & 8 & 4 & 8 \\
\hline Milho (Corn) & 65,04 & 61,47 & 57,90 & 61,87 & 58,33 \\
\hline Semente (Seed) & - & - & - & 4,00 & 8,00 \\
\hline Núcleo ${ }^{1}$ (Nucleus) & 5,00 & 5,00 & 5,00 & 5,00 & 5,00 \\
\hline Óleo de soja (Soybean oil) & 1,5 & 1,5 & 1,5 & 1,5 & 1,5 \\
\hline \multicolumn{6}{|l|}{ Valor calculado (Calculated value) } \\
\hline EM (kcal/kg) (ME) & $3.085,81$ & $3.020,73$ & $2.952,12$ & $3.024,43$ & $2.963,06$ \\
\hline Met+Cys (\%) & 0,76 & 0,69 & 0,67 & 0,68 & 0,66 \\
\hline
\end{tabular}

O teor de gordura foi determinado nas amostras previamente secas em estufa a $65^{\circ} \mathrm{C}$, segundo metodologia descrita por Bligh \& Dyer (1959), que consiste na extração a frio dos lipídeos utilizando-se mistura 1:2: 0,8 de clorofórmio, metanol e água.

A análise de ácidos graxos foi realizada no Departamento de Tecnologia de Alimentos do Instituto de Tecnologia de Alimentos da UFRRJ. As amostras de peito e perna foram descongeladas e trituradas em um processador e depois foram preparadas conforme descrito a seguir: procedeu-se à extração dos lipídeos totais presentes nas amostras segundo metodologia relatada por Bligh \& Dyer (1959). Após a extração, o material foi saponificado e submetido ao processo de metilação, de acordo com metodologia descrita por Hartman \& Lago (1973), e à cromatografia gasosa. Empregou-se cromatógrafo gasoso (Chrompack CP 9001) dotado de detector de ionização em chama de injeção manual, coluna capilar CP-Sil 88, utilizando-se gás hidrogênio como gás de arraste, injetor de spliter razão de 1:100. As condições cromatográficas foram temperatura inicial do forno, $160^{\circ} \mathrm{C}$; temperatura final, $200^{\circ} \mathrm{C}$ com rampa de temperatura a $3^{\circ} \mathrm{C} / \mathrm{min}$.; temperatura do detector, $250^{\circ} \mathrm{C}$; temperatura do injetor, $250^{\circ} \mathrm{C}$; pressão da coluna, $70 \mathrm{Kpa}$; tempo inicial da corrida, $32 \mathrm{~min}$; tempo final da corrida, 10 minutos. Os cálculos foram realizados por meio da integração com um computador ligado ao detector. A identificação dos ácidos graxos foi feita por comparação aos tempos de retenção de um padrão de ácidos graxos de composição conhecida.
O delineamento experimental utilizado foi o inteiramente casualizado em esquema fatorial $2 \times 2+1$ (dois tipos de subprodutos $\times$ dois níveis de inclusão + uma dieta sem resíduos), com quatro repetições por tratamento e dez aves em cada repetição. A análise estatística dos dados foi realizada utilizando-se o Statistical Analisys System (SAS, 2000). A comparação entre as dietas foi realizada por meio de contrastes ortogonais.

\section{Resultados e Discussão}

Os pesos de peito e perna (coxa+sobrecoxa), assim como de fígado, moela e gordura abdominal, não foram influenciados $(\mathrm{P}>0,05)$ pelos níveis de casca e semente de maracujá (Tabela 3). O rendimento de carcaça foi influenciado pelo peso vivo utilizado nas análises estatísticas. Mendes (2001) observou que, em virtude do esvaziamento do trato digestivo provocado pelo jejum alimentar, as aves tendem a apresentar maior rendimento de carcaça.

A deposição de gordura abdominal não foi influenciada $(\mathrm{P}>0,05)$ pelas dietas testadas. Apesar dos maiores valores obtidos na carne da perna, em comparação à do peito, os teores de gordura não foram influenciados pelas dietas e estão de acordo com relatos de Leskanich \& Noble (1997) de que o conteúdo de lipídeo total na carne branca (peito) é de aproximadamente metade do presente na carne escura (perna). 
Tabela 3 - Características de carcaça e teores de gordura nos cortes de frangos de corte alimentados com rações com diferentes níveis de casca ou semente de maracujá

Table 3 - $\quad$ Carcass characteristics of broilers chickens fed diets with different levels of peel or seed of passion fruit

\begin{tabular}{|c|c|c|c|c|c|c|}
\hline \multirow[t]{3}{*}{ Item } & \multicolumn{5}{|c|}{$\begin{array}{c}\text { Ração } \\
\text { Diet }\end{array}$} & \multirow[t]{3}{*}{ CV (\%) } \\
\hline & \multirow{2}{*}{$\begin{array}{c}\text { Controle (\%) } \\
\text { Control } \\
0\end{array}$} & \multicolumn{2}{|c|}{$\begin{array}{c}\text { Casca (\%) } \\
\text { Peel }\end{array}$} & \multicolumn{2}{|c|}{$\begin{array}{l}\text { Semente (\%) } \\
\text { Seed }\end{array}$} & \\
\hline & & 4 & 8 & 4 & 8 & \\
\hline Peso da carcaça (kg) (Carcass weight) & 2,000 & 2,052 & 1,999 & 1,995 & 2,036 & 4,83 \\
\hline Peso do fígado (g) (Liver weight) & 43,59 & 44,15 & 45,23 & 43,20 & 43,64 & 10,41 \\
\hline Peso de moela (g) (Gizzard weight) & 37,49 & 37,18 & 37,34 & 33,63 & 35,03 & 12,50 \\
\hline Peso de gordura abdominal (kg) (Abdominal fat) & 32,79 & 42,94 & 42,01 & 36,14 & 32,80 & 20,94 \\
\hline Rendimento de carcaça (Carcass yield, \%) & 79,80 & 81,60 & 80,20 & 79,10 & 79,30 & 3,31 \\
\hline Gordura na perna (Fat in thigh, \%) & 5,79 & 5,74 & 5,28 & 5,28 & 5,12 & 4,07 \\
\hline Gordura no peito (Fat in breast, \%) & 1,72 & 1,63 & 1,31 & 1,44 & 1,20 & 17,11 \\
\hline
\end{tabular}

Tabela 4 - Teores de ácidos graxos nos músculos do peito de frangos de corte alimentados com rações com diferentes níveis casca ou semente de maracujá (mg/100 g), (\%MS)

Table 4 - Fatty acid content in breast muscle of broilers fed diets with different levels of peel or seed of passion fruit (mg/100 g) (\%DM)

\begin{tabular}{|c|c|c|c|c|c|c|}
\hline \multirow[t]{3}{*}{ Item } & \multicolumn{5}{|c|}{$\begin{array}{c}\text { Ração } \\
\text { Diet }\end{array}$} & \multirow[t]{3}{*}{ CV (\%) } \\
\hline & \multirow{2}{*}{$\begin{array}{c}\text { Controle (\%) } \\
\text { Control } \\
0\end{array}$} & \multicolumn{2}{|c|}{$\begin{array}{c}\text { Casca (\%) } \\
\text { Peel } \\
\end{array}$} & \multicolumn{2}{|c|}{$\begin{array}{c}\text { Semente (\%) } \\
\text { Seed }\end{array}$} & \\
\hline & & 4 & 8 & 4 & 8 & \\
\hline $\begin{array}{l}\text { Ácido mirístico C14:0 } \\
\text { Mirsitic acid }\end{array}$ & 0,0068 & 0,0075 & 0,0095 & 0,0075 & 0,0055 & 52,2 \\
\hline $\begin{array}{l}\text { Ácido palmítico C16:0 } \\
\text { Palmitic acid }\end{array}$ & 0,3768 & 0,3770 & 0,3018 & 0,3233 & 0,2516 & 17,2 \\
\hline $\begin{array}{l}\text { Ácido palmitóleico 16:1 } \\
\text { Palmitoleic acid }\end{array}$ & 0,0584 & 0,0621 & 0,0515 & 0,0449 & 0,0363 & 50,6 \\
\hline $\begin{array}{l}\text { Ácido esteárico C18:0 } \\
\text { Estearic acid }\end{array}$ & 0,1140 & 0,1162 & 0,0886 & 0,1099 & 0,0880 & 19,0 \\
\hline $\begin{array}{l}\text { Ácido oléico C18:1 } \\
\text { Oleic acid }\end{array}$ & 0,5783 & 0,4624 & 0,4334 & 0,3887 & 0,3272 & 25,5 \\
\hline $\begin{array}{l}\text { Ácido linoléico C18:2 } \\
\text { Linoleic acid }\end{array}$ & 0,3511 & 0,3409 & 0,2861 & 0,3262 & 0,3116 & 22,1 \\
\hline $\begin{array}{l}\text { Ácido linolênico C18:3 } \\
\text { Linolenic acid }\end{array}$ & 0,0226 & 0,0144 & 0,0175 & 0,0153 & 0,0137 & 40,6 \\
\hline $\begin{array}{l}\text { Ácido (ADH) docosahexaenóico C22:6 } \\
\text { Docosahexaenoic acid }\end{array}$ & 0,0120 & 0,0153 & 0,0085 & 0,0208 & 0,0168 & 32,5 \\
\hline
\end{tabular}

Os teores de ácidos graxos nos cortes de peito foram influenciados pelos níveis de semente nas rações (Tabela 4). Observou-se redução do teor dos ácidos graxos saturados palmítico (C16: 0) e esteárico (C18: 0) com a inclusão de níveis de $8 \%$ de semente de maracujá na dieta. Resultado semelhante foi observado para o ácido graxo insaturado C22: 6, o docosahexaenóico.

Os resultados podem ter sido influenciados pela composição de ácido linoléico, um ácido graxo insaturado presente nas sementes de maracujá. A composição dos ácidos graxos nos tecidos tende a refletir e pode ser alterada pela composição de ácidos graxos da dieta (Ajuyah et al., 1991; Yau et al., 1991; Scaife et al., 1994; Hrdinka et al., 1996).
A inclusão de ácido linoléico nas dietas não influenciou a deposição deste ácido graxo nos tecidos, contrariando os resultados obtidos em alguns trabalhos, nos quais a utilização de ácidos graxos insaturados nas dietas aumentou sua deposição nos tecidos (Marion \& Woodroof, 1963; Ajuyah et al., 1991; Chanmugam et al., 1992; Sanz et al., 2000; Crespo \& Garcia, 2001).

Na perna, o conteúdo de ácidos graxos saturados foi influenciado significativamente $(\mathrm{P}<0,005)$ pelas rações (Tabela 5). O teor de ácido palmítico (C16) aumentou e o de ácido esteárico diminuiu com a utilização de casca e de semente na dieta, em comparação à ração testemunha. 
Tabela 5 - Teores médios de ácidos graxos nos músculos da perna de frangos de corte alimentados com rações com diferentes níveis de casca ou semente de maracujá (mg/100g) (\%MS)

Table 5 - Fatty acids contents in thigh muscle of broilers chickens fed diets with different levels of peel or seed of passion fruit (g/100 g) (\%DM)

\begin{tabular}{|c|c|c|c|c|c|c|}
\hline \multirow[t]{3}{*}{ Item } & \multicolumn{5}{|c|}{$\begin{array}{c}\text { Ração } \\
\text { Diet }\end{array}$} & \multirow[t]{3}{*}{ CV (\%) } \\
\hline & \multirow{2}{*}{$\begin{array}{c}\text { Controle }(\%) \\
\text { Control } \\
0\end{array}$} & \multicolumn{2}{|c|}{$\begin{array}{c}\text { Casca }(\%) \\
\text { Peel }\end{array}$} & \multicolumn{2}{|c|}{$\begin{array}{l}\text { Semente }(\%) \\
\text { Seed }\end{array}$} & \\
\hline & & 4 & 8 & 4 & 8 & \\
\hline $\begin{array}{l}\text { Ácido mirístico C14:0 } \\
\text { Mirsitic acid }\end{array}$ & 0,0330 & 0,0303 & 0,0293 & 0,0273 & 0,0227 & 21,53 \\
\hline $\begin{array}{l}\text { Ácido palmítico C16:0 } \\
\text { Palmitic acid }\end{array}$ & 0,5785 & 1,2946 & 1,1942 & 1,1561 & 1,0352 & 26,30 \\
\hline $\begin{array}{l}\text { Ácido palmitóleico 16:1 } \\
\text { Palmitoleic acid }\end{array}$ & 0,3325 & 0,3075 & 0,2776 & 0,2641 & 0,2304 & 26,90 \\
\hline $\begin{array}{l}\text { Ácido esteárico C18:0 } \\
\text { Estearic acid }\end{array}$ & 1,6696 & 0,3559 & 0,3092 & 0,3287 & 0,3152 & 79,25 \\
\hline $\begin{array}{l}\text { Ácido oléico C18:1 } \\
\text { Oleic acid }\end{array}$ & 1,5375 & 2,0535 & 1,9146 & 1,8441 & 1,6729 & 23,40 \\
\hline $\begin{array}{l}\text { Ácido linoléico C18:2 } \\
\text { Linoleic acid }\end{array}$ & 0,3655 & 1,2036 & 1,1652 & 1,2648 & 1,4283 & 28,71 \\
\hline $\begin{array}{l}\text { Ácido linolênico C18:3 } \\
\text { Linolenic acid }\end{array}$ & 0,0260 & 0,0667 & 0,0587 & 0,0667 & 0,0745 & 44,59 \\
\hline $\begin{array}{l}\text { Ácido (ADH) docosahexaenóico C22:6 } \\
\text { Docosahexaenoic acid }\end{array}$ & 0,0033 & 0,0534 & 0,0081 & 0,0208 & 0,0239 & 148,92 \\
\hline
\end{tabular}

Diferente do peito, os subprodutos de maracujá aumentaram os níveis de ácidos graxos insaturados na perna. Os teores dos ácidos linoléico (C18:2) e linolênico (C18: 3) foram maiores nos tecidos dos frangos alimentados com as rações contendo subprodutos de maracujá, principalmente no nível de $8 \%$ de semente nas rações. Esses resultados corroboram outros estudos já realizados, nos quais a suplementação de ácidos graxos insaturados aumentou o conteúdo desses ácidos nos tecidos e reduziu o de ácidos graxos saturados (Ajuyah et al., 1991; Chanmugan et al., 1992; Scaife et al., 1994; Gonzalez-Esquerra \& Leeson, 2000). O conteúdo de ácido linoléico das sementes possivelmente contribuiu como fonte suplementar de ácido linoléico nas rações.

\section{Conclusões}

A utilização de subprodutos de maracujá em dietas para frangos de corte aumenta significativamente os níveis de ácidos graxos insaturados, tanto da família ômega 3 como da ômega 6, nos músculos da perna. Com a inclusão de sementes e casca de maracujá, a deposição de ácidos graxos saturados foi menor nos músculos do peito e da perna.

\section{Agradecimento}

À indústria de sucos Curumatã, localizada em São Francisco de Itabapoana, RJ, pelo fornecimento dos subprodutos de maracujá utilizados no experimento.

\section{Literatura Citada}

ARIKI, J.; RUGIERO, C.; TOLEDO, P.R. et al. Aproveitamento de cascas desidratadas e sementes de maracujá amarelo (Passiflora edulis $f$. flavicarpa deg.) na alimentação de frangos de corte. Científica, v.5, n.3, p.340-343, 1977.

AJUYAH, A.O.; LEE, K.H.; HARDIN, R.T. et al. Changes in the yield and in the fatty acid composition of whole carcass and selected meat portions of broiler chickens fed full fat oil seeds. Poultry Science, v.70, p.2304-2314, 1991.

BLIGH, E.G.; DYER, W.J. A rapid method of total lipid extraction and purification. Canadian Journal Biochemistry Physiology, v.37 p.911-917, 1959.

CHANMUGAM, P.; BOUdREAU, M.; BOUTTE, T. et al. Incorporation of different types of n-3 Fatty Acids into tissue lipids of poultry. Poultry Science, v.71, p.516-521, 1992.

CRESPO, N.; ESTEVE-GARCIA, E. Dietary fatty acid profile modifies abdominal fat deposition in broiler chickens. Poultry Science, v.80, p.71-78, 2001.

GONZALEZ-ESQUERRA; LEESON, S. Effects of menhaden oil and flaxseed in broiler diets on sensory quality and lipid composition of poultry meat. British Poultry Science, v.41, p.481-488, 2000.

HARTMAN, L.; LAGO, R.C.A. Rapid preparation of fatty acid methyl esters from lipids. Laboratory Practice, v.22 n.8, p.4175-476, 1973.

HRDINKA, C.; ZOLLITSCH, W.; KNAUS, W. et al. Effects of dietary fatty acid pattern on melting point and composition of adipose tissue and intramuscular fat of broiler carcasses. Poultry Science, v.75, p.208-215, 1996.

LEONEL, S.; LEONEL, M.; DUARTE FILHO, J. Principais produtos e subprodutos obtidos do maracujazeiro. Informe Agropecuário, v.21, n.206, p.86-88, 2000.

LESKANICH, C.O.; NOBLE, R.C. Manipulation of the n-3 polyunsaturated fatty acid composition of avian eggs and meat. World's Poultry Science Journal, v.53, p.155-183, 1997.

MARION, J.E.; WOODROOF, J.G. The fatty acid composition of breast, thigh and skin tissues of chicken broilers as influenced by dietary fats. Poultry Science, v.42, p.1-6, 1963. 
MENDES, A.A. Rendimento e qualidade da carcaça de frangos de corte. In: CONFERÊNCIA APINCO 2001, Campinas. Anais... Campinas: Fundação Apinco de Ciência e Tecnologia Avícolas, 2001. v.2, p.79-100.

OLIVEIRA, L.F.; NASCIMENTO, M.R.F.; BORGES, S.V. et al. Aproveitamento alternativo da casca do maracujá amarelo (Passiflora edulis f. flavicarpa deg.) para produção de doce em calda. Ciência e Tecnologia de Alimentos, v.22, n.3, p.259262, 2002.

PINCHASOV, Y.; NIR, I. Effect of dietary polyunsaturated fatty acid concentration on performance, fat deposition and carcass fatty acid composition in broiler chickens. Poultry Science, v.71, p.1504-1512, 1992.

ROSTAGNO, H.S. Tabelas brasileiras para aves e suínos: composição de alimentos e exigências nutricionais. Viçosa, MG: Editora UFV, 2000. 141p.
SANZ, M.; FLORES, A.; LOPEZ-BOTE, C.J. The metabolic use of energy from dietary fat in broilers is affected by fatty acid saturation. British Poultry Science, v.41, p.61-68. 2000.

STATISTICAL ANALYSIS SYSTEM - SAS. SAS user's guide: statistics. Versão 8, Cary: 2000. (CD-ROM).

SCAIFE, J.R.; MOYO, J.; GALBRAITH, H. et al. Effect of different dietary supplemental fats and oils on the tissue fatty acid composition and growth of female broilers. British Poultry science, v.35, p.107-118, 1994.

YAU, J.C.; DENTON, H.; BAILEY, C.A. et al. Customizing the fatty acid content of broiler tissues. Poultry Science, v.70, p.167-172, 1991. 